\title{
D-Dimer plasma levels in patients with coronary artery disease
}

\section{Níveis plasmáticos de Dímero $\mathrm{D}$ em pacientes com doença arterial coronariana}

Luciana M. Lima ${ }^{1}$

Marinez O. Sousa ${ }^{1}$

Ana Paula Fernandes ${ }^{1}$

Adriano P. Sabino ${ }^{1}$

Cirilo P. Fonseca Neto ${ }^{2}$

José Carlos F. Garcia ${ }^{2}$

Jamil A. Saad ${ }^{2}$

Maria das Graças Carvalho ${ }^{1}$

\begin{abstract}
We have previously reported that prothrombin fragment $1+2$ levels were not associated to the presence or severity of coronary artery disease (CAD) and do not provide further information on subjects with CAD diagnosed by angiography. Thus, in the present study another marker of hypercoagulability was evaluated in the same subjects. This study aimed at determining D-Dimer plasma levels in a group of subjects undergoing coronary angiography to establish a likely relation between this parameter and the severity of CAD. D-Dimer plasma levels were determined in 17 subjects with no coronary atheromatosis (controls), 12 subjects with mild/ moderate atheromatosis and 28 subjects with severe atheromatosis. No significant differences were observed among the three groups. Data analysis enables an inference on a tendency towards an increase in fibrinolytic activity in patients with atheromatosis, reflected by the increase in D-Dimer concentrations in the severe atheromatosis group in subjects with CAD diagnosed by coronary angiography. Rev. bras. hematol. hemoter. 2006;28(4):280-283.
\end{abstract}

Palavras-chave: D-Dimer; coronary artery disease; coronary angiography.

\section{Introduction}

Several decades of clinic and laboratory research have pointed out the association between hemostatic system constituents and $\mathrm{CAD}^{1-3}$ investigating the possible predictive value of these constituents in the progression of the disease. Both coagulation and fibrinolytic systems play an important role in the clinically silent evolution and progression of atheroma and in events that follow the rupture of the plaque resulting in clinical symptoms. ${ }^{4}$ Thrombus formation in a disrupted atherosclerotic plaque triggers most of the cardiovascular ischemic events. As the thrombus is dissolved by the fibrinolytic system, ${ }^{5}$ researchers hypothesized that a decrease in fibrinolytic activity could be a risk factor for ischemic events. ${ }^{3,6,7}$

D-Dimer fragments are produced when plasmin, an enzyme that activates fibrinolytic system, ${ }^{8}$ degrades fibrin to remove it from blood vessels, ducts and organic fluids. ${ }^{9}$
When the conversion of fibrinogen in fibrin takes place, the mechanism that keeps the hemostatic balance is activated, with the conversion of plasminogen to plasmin, for fast removal of fibrin, preventing thrombotic complications. ${ }^{10} \mathrm{D}$-Dimer plasma levels evaluate not only the activation of the fibrinolytic system, but also the severity of a hypercoagulability condition. ${ }^{11}$

We have previously reported that prothrombin fragment $1+2$ levels were not associated to the presence or severity of CAD and do not provide further information on subjects with coronary artery disease (CAD) diagnosed by angiography. ${ }^{12}$

Thus, in the present study another marker of hypercoagulability was evaluated in the same subjects. This study aimed at determining of D-Dimer plasma levels in a group of subjects submitted to coronary angiography, trying to establish a possible relationship between this parameter and the severity of CAD.

${ }^{1}$ Faculdade de Farmácia - Universidade Federal de Minas Gerais, Belo Horizonte, MG, Brasil.

${ }^{2}$ Hospital Socor, Belo Horizonte, MG, Brasil.

Correspondence: Marinez Oliveira Sousa

Faculdade de Farmácia, Universidade Federal de Minas Gerais

Av. Antônio Carlos, 6627

31270-901 - Belo Horizonte-MG - Brasil

Phone: 55.31.3499.6896 - Fax: 55.31.3499.6985

e-mail: marinez@farmacia.ufmg.br 


\section{Materials and Methods}

The protocol of this study had approval from ethical and formal points of view by both Research Ethics Committees of Socor Hospital and Federal University of Minas Gerais. The subjects selected to take part in this research were informed about the aims of the study and those who agreed signed informed consent forms. A clinical form reporting important data was filled in for all cases. Fifty-seven subjects, with ages ranging from 40 to 65 years, who had been submitted to coronary angiography in the Department of Hemodynamics of Socor Hospital, Belo Horizonte, Brazil, were selected. Seventeen subjects (controls) did not present atheromatosis in the coronary arteries, 12 subjects presented mild/moderate atheromatosis and 28 subjects, severe atheromatosis (Table 1). Subjects with previous histories (up to 3 months) of acute coronary syndrome; oral anticoagulants, hypolipemiant drugs or estrogen use; carriers of intercurrent diseases, such as coagulation disorders, kidney, liver and autoimmune diseases, diabetes mellitus and cancer were excluded from the study.

Coronary angiography was performed by the Judkins' technique; films were examined by three experienced cardiologists and decisions made according to defined criteria considering stenosis of one or more arteries: up to $30 \%$ stenosis it was classified as mild atheromatosis; from 30 to $70 \%$ stenosis as moderate atheromatosis and above $70 \%$ stenosis as severe atheromatosis.

Venous blood samples were obtained after 12 hours of fasting and collected in tubes containing $3.2 \mathrm{w} / \mathrm{v}$ sodium citrate as anticoagulant. Blood samples were centrifuged at 2500 rpm for 10 minutes to obtain plasma.

Plasma D-Dimer levels were determined using the VIDAS D-Dimer New Kit (BioMérieux ${ }^{\circledR}$ - France) in a MiniVidas (BioMérieux ${ }^{\circledR}$ ) device according to the manufacturer's instructions. Its analytical principle is an enzyme linked fluorescent assay (ELFA). In principle, the test samples were

Table 1

Characterization of the studied groups according to gender, age and body mass index (BMI) expressed as mean and standard deviation and the D-Dimer assay results. There were no significant differences between the studied groups with regards to age, BMI and D-Dimer plasma levels

\begin{tabular}{|c|c|c|c|}
\hline Parameter & Control & $\begin{array}{l}\text { Mild/moderate } \\
\text { atheromatosis }\end{array}$ & $\begin{array}{c}\text { Severe } \\
\text { atheromatosis }\end{array}$ \\
\hline $\mathrm{n}(\mathrm{M} / \mathrm{F})$ & $17(8 / 9)$ & $12(8 / 4)$ & $28(16 / 12)$ \\
\hline Age (years) & $58.9 \pm 7.7$ & $61.0 \pm 11.6$ & $60.9 \pm 9.6$ \\
\hline BMI $\left(\mathrm{Kg} / \mathrm{m}^{2}\right)$ & $24.9 \pm 4.6$ & $26.1 \pm 4.9$ & $24.3 \pm 3.2$ \\
\hline Mean $\pm S D$ & $478.8 \pm 401.6$ & $767.0 \pm 1056.7$ & $679.4 \pm 579.0$ \\
\hline D-Dimer & 334.1 & 354.1 & 535.0 \\
\hline $\begin{array}{l}\text { Interquartile } \\
\text { range }\end{array}$ & $262.5-622.6$ & $253.7-682.2$ & $337.5-778.2$ \\
\hline
\end{tabular}

$\mathrm{n}=$ sample size, $\mathrm{M}=$ male, $\mathrm{F}=$ female, $\mathrm{SD}=$ standard deviation transferred into wells containing an alkaline-phosphatase labeled anti-D-D monoclonal antibody. The sample/conjugate mixture was cycled in and out of the solid phase receptacle (SPR) several times to increase the reaction speed. Unbound components were eliminated during washing phases. The addition of the substrate (4-methyl-umbelliferyl phosphate) and its subsequent hydrolysis by conjugate enzyme produces a fluorescent product (4-methyl-umbelliferone), which is measured at $450 \mathrm{~nm}$. The values were then automatically calculated by the instrument in relation to two calibration curves performed using two calibrators provided by the manufacturer, corresponding to the two detection steps. All of the assay steps were performed automatically by the instrument. The lower limit of detection for the assay was $45 \mathrm{ng} / \mathrm{mL}$. The intra and inter assay coefficients of variations for $488 \mathrm{ng} / \mathrm{mL}$ D-Dimer were $2.9 \%$ and $6.8 \%$, respectively (BioMérieux, Marcy-I'Etoile, France).

Data were analyzed by Sigma Stat version 1.0 software system using one-way analysis of variance (ANOVA) after log-transformation of the data, which did not present normal distribution. Pearson's correlation coefficient was used to measure the linear association between D-Dimer and Plasma F1+2 levels. Differences were considered statistically significant when $\mathrm{p}$-value $<0.05$.

\section{Results}

The results for the biomarker assay are shown as mean and standard deviations, and median and interquartile ranges in Table 1. Statistically significant differences were not found among the three groups. However, the plasma D-Dimer levels showed a positive and significant association with F1+2 levels ( $r=0.50, p<0.0001)$. Figure 1 present the distribution of the values for $\mathrm{D}$-Dimer plasma levels.

\section{Discussion}

Several authors have showed the association between high D-Dimer levels with the presence of CAD and their results support the concept of the contribution of intravascular fibrin in atherothrombogenesis. ${ }^{13}$ However, few studies assessed the association between severity of CAD and D-Dimer plasma levels. Koenig et al. ${ }^{14}$ were unable to find any association between $\mathrm{D}$ Dimer concentration and severity and extent of $\mathrm{CAD}$, considering percentage of stenosis and number of coronary arteries affected. Similar results were obtained in this study, since data showed that there were no significant differences for D-Dimer plasma levels among the groups studied (Table 1$)$. The presence of one very high value (3867.4 ng/mL, Figure 1) in the mild/ moderate atheromatosis group contributed to 




Figure 1. The distribution of plasma D-Dimer levels in controls, MMA (mild/moderate atheromatosis) and SA (severe atheromatosis). Each box represents the median and interquartile range of values, with the I bars (whiskers) extended to the minimum and maximum. The shaded area corresponds to the reference range (up to $500 \mathrm{ng} / \mathrm{ml}$ )

the average value in this group being higher than that in the severe atheromatosis group. The patient with very high DDimer plasma levels had had an episode of deep venous thrombosis one year previous to blood collection, maybe justifying, in part, this finding. High D-Dimer concentrations are consistently associated to venous thromboembolism episodes ${ }^{3}$ and normal D-Dimer plasma levels are used to exclude the presence of deep venous thrombosis.

Analysis of data presented in Table 1 enables the inference on a tendency of fibrinolytic activity increases in patients with atheromatosis reflected by the increase of DDimer concentrations in severe atheromatosis group, since the average value for this group is higher than the normal range for the method (500 $\mathrm{ng} / \mathrm{mL}$ ) and higher than the average value obtained for the control group, that was within the normal range. Similar inference can be made analyzing the medians of the three groups studied (Table 1). The occurrence of an extremely high value in the mild/moderate atheromatosis group had a significant influence on the mean value and on the standard deviation value of this group. Extreme values have strong influences on the mean value, but little influence on median. An analysis of the medians obtained enables the inference of a gradual rise in D-Dimer levels consistent with coronary atherosclerosis progression, but without statistically significant differences between the groups.

It is accepted that D-Dimer plasma levels represent a direct indication of fibrinolysis. However, this statement does not take into account the involvement of activators and inhibitors of the fibrinolytic system, such as tissueplasminogen activator (t-PA) and type 1-plasminogen activator inhibitor (PAI-1) concentrations, parameters not evaluated in this study. Data herein presented do not enable a conclusion on the association between fibrinolytic activity and severity of CAD in the subjects studied, since the results obtained for D-Dimer plasma determinations did not show statistically significant differences and the activities of the activators and inhibitors were not evaluated. It is likely that D-Dimer levels were not significantly higher in severe CAD patients due to a probable PAI-1 increase, inhibitor that frequently is elevated in cardiovascular diseases, ${ }^{2}$ resulting in a decrease in the performance of the fibrinolytic system evidenced by D-Dimer levels lower than those expected in severe atheromatosis patients.

Lassila et al. ${ }^{15}$ showed that the severity of peripheral atherosclerosis was proportional to the levels of D-Dimer, but usually peripheral arterial disease involves a greater extent of atheromatosis and results in higher D-Dimer plasma levels. ${ }^{3}$ There is evidence in the literature that a moderate increase in D-Dimer reflects in less thrombin formation and intravascular fibrin production, but this increase may be relevant in CAD. ${ }^{3}$ In this study, we showed a positive and significant correlation between D-Dimer and Plasma F1+2 levels ( $\mathrm{r}=0.50$, $\mathrm{p}<0.0001$ ), considering all 57 participants, as has been reported previously by other authors. ${ }^{16,17}$ The correlation suggests an increase of fibrinolytic activity according to thrombin generation in the studied population.

Data analysis enables an inference on a tendency towards an increase in fibrinolytic activity in patients with atheromatosis, reflected by the increase in D-Dimer concentrations in the severe atheromatosis group in subjects with CAD diagnosed by coronary angiography, and suggests a greater fibrin deposition with consequent action of the fibrinolytic system.

\section{Resumo}

Em estudo prévio, os níveis plasmáticos do fragmento $1+2$ da protrombina não foram associados com a presença ou com a gravidade da doença arterial coronariana (DAC), não trazendo benefício adicional pelo menos em indivíduos com diagnóstico de DAC estabelecido por angiografia. Desta forma, neste estudo outro marcador de hipercoagulabilidade foi avaliado nos mesmos pacientes. O presente estudo teve como objetivo determinar os níveis plasmáticos do dímero $D$ de um grupo de indivíduos submetidos à angiografia coronariana, buscando estabelecer a possível correlação entre este parâmetro e a gravidade da DAC. Os níveis plasmáticos do dímero $D$ foram determinados em amostras de sangue de 17 indivíduos com ausência de ateromatose nas coronárias (controles), 12 indivíduos apresentando ateromatose leve/moderada e 28 indivíduos apresentando ateromatose grave. Não foram encontradas diferenças estatisticamente significativas entre as médias dos três grupos para o parâmetro avaliado. Uma análise dos dados permite inferir sobre uma tendência ao aumento da atividade fibrinolítica nos pacientes com ateromatose, refletida pela elevação da concentração de dímero $D$ no grupo ateromatose grave em indivíduos com diagnóstico de DAC estabelecido por angiografia coronariana. Rev. bras. hematol. hemoter. 2006; 28(4):280-283.

Palavras-chave: Dímero D; doença arterial coronariana; angiografia coronariana. 


\section{Acknowledgement}

We are very grateful to Capes, CNPq and Fapemig for financial support.

\section{References}

1. Hoffmeister A, Rothenbacher D, Khuseyinova $\mathrm{N}$ et al. Plasminogen levels and risk of coronary artery disease. Am J Cardiol 2002; 90:1.168-70.

2. Folsom AR, Aleksic N, Park E et al. Prospective study of fibrinolytic factors and incident coronary artery disease. The Atherosclerosis Risk in Communities (ARIC) Study. Arterioscler Thromb Vasc Biol 2001;21:611-17.

3. Danesh J, Whincuo P, Walker M et al. Fibrin D-Dimer and coronary heart disease. Prospective study and meta-analysis. Circulation 2001;103:2.323-27.

4. Salomaa V, Rasi V, Kulathinal S et al. Hemostatic factors as predictors of coronary events and total mortality - the FINRISK 92 hemostasis study. Arterioscler Thromb Vasc Biol 2002;22:353-8.

5. Handin RI, Lux SE, Stossel TP. (Ed.). Blood: Principles of Hematology. Philadelphia: J.B. Lippincott, 1995. 2305p.

6. Thompson SG Kienast J, Pyke SDM et al. Hemostatic factors and the risk of myocardial infarction or sudden death in patients with angina pectoris. European Concerted Action on Thrombosis and Disabilities Angina Pectoris Study Group. N Eng J Med 1995; 332: 635-41.

7. Salomaa V, Stinson JD, Kark JD et al. Association of fibrinolytic parameters with early atherosclerosis: The ARIC Study. Circulation 1995;92:284-90.

8. Syrovets $\mathrm{T}$, Simmet $\mathrm{T}$. Novel aspects and new roles for the serine protease plasmin. Cell Mol Life Sci 2004;6:873-85.

9. Scazziota A, Altman R. El mecanismo de la hemostasia normal. Rev Iberoamer Thromb Hemostasia 1996;1:9-26.

10. Lijnen HR, Collen D. Mechanisms of physiological fibrinolysis. Baillieres Clin Haematol 1995;8:277-90.

11. Matsuo T, Kobayashi H, Kario $\mathrm{K}$ et al. Fibrin D-dimer in thrombogenic disorders. Semin Thromb Haemost 2000;26:101-7.

12. Lima LM, Sousa MO, Fernandes AP et al. Fragmento $1+2$ da protrombina em indivíduos submetidos à angiografia coronariana. Rev Bras Hematol Hemoter 2005;27:188-191.

13. Tataru MC, Heinrich J, Junker R et al. D-dimer in relation to the severity of arteriosclerosis in patients with stable angina pectoris after myocardial infarction. Eur Heart J 1999;20:1.493-502.

14. Koenig W, Rothenbacher D, Hoffmeister A et al. Plasma fibrin DDimer levels and risk of stable coronary artery disease: results of a large case-control study. Arterioscler Thromb Vasc Biol 2001; 21:1.701-05.

15. Lassila R, Peltonen S, Lepantalo M et al. Severity of peripheral atherosclerosis is associated with fibrinogen and degradation of cross-linked fibrin. Artherioscler Thromb 1993;13:1.738-42.

16. Réganon E, Vila V, Martínez-Sales V et al. Inflammation, fibrinogen and thrombin generation in patients with previous myocardial infarction. Haematologica 2002;87:740-745.

17. Lowe GDO, Rumley A, Sweetnam PM et al. Fibrin D-dimer, markers of activation and the risk of major ischaemic heart disease in the Caerphilly Study. Thromb Haemost 2001;85:822-827.

Avaliação: Editor e dois revisores externos

Conflito de interesse: não declarado

Recebido: 09/05/2006

Aceito: 01/07/2006 